\title{
Antifungal defensins and their role in plant defense
}

\author{
Ariane F. Lacerda ${ }^{1,2}$, Érico A. R. Vasconcelos ${ }^{2,3}$, Patrícia Barbosa Pelegrini ${ }^{2}$ and Maria F. Grossi de Sa ${ }^{2,3}$ * \\ ${ }^{1}$ Department of Biochemistry and Molecular Biology, Federal University of Rio Grande do Norte, Natal, Brazil \\ ${ }^{2}$ Plant-Pest Interaction Laboratory, Embrapa - Genetic Resources and Biotechnology, Brasilia, Brazil \\ ${ }^{3}$ Catholic University of Brasilia, Brasilia, Brazil
}

\section{Edited by:}

Tzi Bun Ng, The Chinese University of

Hong Kong, China

\section{Reviewed by:}

Noton Kumar Dutta, Johns Hopkins University, USA

Dmitri Debabov, NovaBay

Pharmaceuticals, USA

*Correspondence:

Maria F. Grossi de Sa, Plant-Pest Interaction Laboratory, EmbrapaGenetic Resources and

Biotechnology, PqEB Avenue W5

Norte (final), P. O. BOX 02372 ,

Brasilia, DF 70770-917, Brazil

e-mail: fatima.grossi@embrapa.br
Since the beginning of the 90s lots of cationic plant, cysteine-rich antimicrobial peptides (AMP) have been studied. However, Broekaert etal. (1995) only coined the term "plant defensin," after comparison of a new class of plant antifungal peptides with known insect defensins. From there, many plant defensins have been reported and studies on this class of peptides encompass its activity toward microorganisms and molecular features of the mechanism of action against bacteria and fungi. Plant defensins also have been tested as biotechnological tools to improve crop production through fungi resistance generation in organisms genetically modified (OGM). Its low effective concentration towards fungi, ranging from 0.1 to $10 \mu \mathrm{M}$ and its safety to mammals and birds makes them a better choice, in place of chemicals, to control fungi infection on crop fields. Herein, is a review of the history of plant defensins since their discovery at the beginning of 90s, following the advances on its structure conformation and mechanism of action towards microorganisms is reported. This review also points out some important topics, including: (i) the most studied plant defensins and their fungal targets; (ii) the molecular features of plant defensins and their relation with antifungal activity; (iii) the possibility of using plant defensin(s) genes to generate fungi resistant GM crops and biofungicides; and (iv) a brief discussion about the absence of products in the market containing plant antifungal defensins.

Keywords: plant defensins, antifungal, phytopathogens, peptide structure, peptide function, transgeny

\section{INTRODUCTION}

Plants are constantly exposed to several pests and pathogens in nature. They have developed complex defense mechanisms to protect themselves against the attack of pathogens (Gachomo etal., 2003, 2010). To circumvent these occurrences, defense factors are produced, including, hydrogen peroxide, phenolics, terpenoids, alkaloids, polyacetylenes, and a diverse array of pathogenesis-related (PR) defense proteins (Broekaert et al., 1997; Garcia-Olmedo et al., 1998; Osbourn, 1999; Van Loon et al., 2006; Benko-Iseppon etal., 2010) and plant defensins (Terras et al., 1995).

Defensins are small cationic peptides of 45-54 amino acid residues with a conserved signature of cysteines, which can form three to four disulfide bridges. Plant defensins exhibit a conserved tertiary structure that consists of a triple-stranded antiparallel $\beta$ sheet and one $\alpha$-helix that are stabilized into a compact shape by the disulfide bridges. These bridges form a cysteine-stabilized $\alpha$-helix $\beta$-sheet motif $(C S \alpha / \beta)$ (Kobayashi et al., 1991; Zhu et al., 2005). In addition to the $C S \alpha / \beta$ motif, two additional conserved motives, named $\alpha$-core, encompassing the loop connecting the first $\beta$-strand to the $\alpha$-helix, and the $\gamma$-core containing the hairpin loop that links $\beta$-strands 2 and 3 ( $L \beta 2 \beta 3$ ) were also present in the defensin structure (Yount and Yeaman, 2004; Yount et al., 2007). Despite the low level of amino acid sequence identity between defensins, their three dimensional structures are remarkably similar between different plant defensins (Pelegrini and Franco, 2005). Variations in the amino acids are reflected by small conformational changes in the tertiary structure that contribute to the broad range of biological activities in these proteins. Only one amino acid substitution can change the spectrum of activity exhibited by these peptides (Carvalho and Gomes, 2011).

Since the beginning of 1990s, lots of cationic plant cysteine-rich antimicrobial peptides (AMP) have been studied. Plant defensins were first described in the seeds of wheat (Triticum turgidum) and barley (Hordeum vulgare) (Colilla et al., 1990; Mendez et al., 1990). They were characterized as a new member of the thionine family due to their similarity in molecular mass, amino acid sequence and number of cysteines. However, subsequent studies performed by Bruix et al. (1995) revealed the existence of differences in the pattern of the disulfide bridges, demonstrating that these two peptide families are unrelated. Broekaert et al. (1995) renamed these peptides as "plant defensins," after comparing their structural and functional resemblance to previously characterized AMPs found in insects and mammals.

\section{DEFENSINS AND THEIR CONTRIBUTION TO PLANT DEFENSE HOW CAN DEFENSINS HAVE A ROLE IN PLANT DEFENSE?}

The role of defensins in the preformed defense of plants is well reported. Several reports show that defensins are an integral part of the plant innate immune system. Most plant defensins already characterized show a constitutive pattern of expression with up regulation in response to pathogen attack, injury and some abiotic stresses (de Beer and Vivier, 2011).

Several features make clear that defensin peptides are involved in plant defense (Selitrennikoff, 2001). Their distribution is consistent with their putative defense role. They have been 
identified in leaves, tubers, flowers, pods and seeds, playing an important role in the protection of germinating seeds and developing seedlings (Garcia-Olmedo et al., 1998). In addition, plant defensins are also localized in the xylem, stomata, and stomata cells, parenchyma cells, and other peripheral areas (Kragh etal., 1995; Segura etal., 1998; Chen et al., 2002). The presence in the different tissues is consistent with a defensive role of such peptides, once it is believed that such sites are the place of the first contact with a potential pathogen (Carvalho and Gomes, 2011).

Moreover, plant defensins have a broad spectrum of in vitro antimicrobial activity and, currently, there are several reports describing the production of transgenic plants constitutively expressing foreigner defensins. Hence, they possess an enormous multiplicity of biological activities, such as antimicrobial, insecticidal, inhibiting protein synthesis, mediating abiotic stress, and $\mathrm{Zn}$ tolerance, and as inhibitors of digestive enzymes (Carvalho and Gomes, 2009, 2011). According to Franco (2011), these defense peptides are classified as promiscuous proteins, as they show numerous biological activities. As an example, there is the family of defensins isolated from Vigna unguiculata, in which different homologous forms may act as antifungal, antibacterial, and enzyme inhibitors (Franco, 2011). Although they present multiple functions, the antimicrobial activity of plant defensins is mainly observed against fungi.

Therefore, the present review explores the current knowledge about the structure and mechanism of action of plant defensins with emphasis on its activity against phytopathogenic fungi. Furthermore, we describe the current use of these peptides as biotechnological tools in the production of transgenic plants that could result in the future release of agronomically important crops resistant to various diseases.

\section{STRUCTURAL CONFORMATION AND MECHANISM OF ACTION}

Plant defensins present a well-conserved three-dimensional structure composed by a cysteine-stabilized $\alpha / \beta(\mathrm{CS} \alpha \beta)$ motif, which forms one $\alpha$-helix followed by three anti-parallel $\beta$-sheets. The amino acid sequence is also quite conserved, especially due to the presence of six to eight cysteine residues, which form three to four disulfide bridges in the sequence of Cys1-Cys8, Cys2-Cys5, Cys3-Cys6, and Cys4-Cys7 (Lay and Anderson, 2005). Nevertheless, plant defensins with five disulfide bonds have been described, such as the peptide from Petunia hybrida (PhD1), whose cysteine residues interact in the following order: Cys1-Cys10, Cys2-Cys5, Cys3-Cys7, Cys4-Cys8, and Cys6-Cys9 (Janssen et al., 2003). The additional disulfide bond does not affect the typical three-dimensional structure of the defensin, which is located after the $\alpha$-helix and the first $\beta$-sheet (Janssen et al., 2003).

Furthermore, plant defensins with alternative structures have been identified in the literature, including defensins from Nicotiana alata (NaD1), Petunia hybrida (PhD1 and $\mathrm{PhD} 2)$, and ZmESR6 isolated from developing maize kernels. These defensins contain an extra acidic C-terminal prodomain whose function is still unknown, although it has been suggested that it is involved in vacuolar targeting or in eliminating potential detrimental effects caused by the basic nature of the defensin (De Coninck et al., 2013).

As they are peptides consisting of 45-54 amino acid residues, structural studies on crystallography and nuclear magnetic resonance (NMR) have been widely extended during the last few years. Among the peptides with antifungal activity, whose structures have been elucidated, are included the defensins from Nicotiana alata (NaD1), Pachyrrhizus erosus (SPE10), Petunia hybrida (PhD1), Pisum sativum (Psd1), Raphanus sativus (Rs-AFP1), and Saccharum officinarum (Sd5) (Fant et al., 1998; Almeida et al., 2002; Janssen etal., 2003; Lay et al., 2003; de Paula et al., 2011; Song et al., 2011; Van der Weerden and Anderson, 2013; Figure 1). An amino acid sequence alignment of antifungal defensins from plants shows that they do not present conservative amino acid sequences, except the cysteine residues and a glycine residue positioned in the second $\beta$-sheet (Pelegrini and Franco, 2005; Van der Weerden and Anderson, 2013). According to their structural features, plant defensins show a conserved $\gamma$-core signature classified as the dextromeric isoform, which is related to the amino acid sequence conservation of the region $\mathrm{NH}_{2} \ldots\left[\mathrm{X}_{1-3}\right]-[\mathrm{GXC}]=\left[\mathrm{X}_{3-9}\right]-[\mathrm{C}] \ldots \mathrm{COOH}$ (Figures 1 and 2). This preservation in the primary sequence gives them a threedimensional conformation denominated $\gamma$-core motif, consisting of two antiparallel $\beta$-sheets, with an interpolated turn region. Earlier studies classified plant defensins as belonging to the $\beta-\gamma-\alpha$ Group, according to their relative structural $\gamma$-core (Yount and Yeaman, 2004). It has been described that the $\gamma$-core motif is important for antimicrobial activity in disulfide-stabilized peptides (Yount and Yeaman, 2004), not only for their cysteine content, but especially due to the presence of positively charged residues at the second $\beta$-turn of their structure (Fant et al., 1998). This characteristic was first observed when the structure of $R$. sativus defensin 1 (Rs-AFP1) was determined by ${ }^{1} \mathrm{HNMR}$, and mutation analyzes was also performed using the peptide isoform Rs-AFP2 (De Samblanx et al., 1997; Fant et al., 1998). In both cases, it was demonstrated that positively-charged amino acids located at the $\gamma$-core motif were essential for the antifungal activity of theses peptides, and the substitution of neutral residues inside this $\gamma$ core by other positively-charged amino acid residues increased their activity towards pathogenic fungi. Spelbrink et al. (2004), while studying defensins from Medicago trunculata, verified that the antifungal activity of MtDef1 was due to the presence of four positively-charged amino acids, also located in the $\gamma$-core region, which was lacking in the structure of the non-antifungal peptide MtDef2. Moreover, in vitro assays revealed that this region might be involved in the ability of MtDef1 to block L-type $\mathrm{Ca}++$ channels in mammalian cells.

There are two major hypothesis that tries to explain the mechanism of action of antimicrobial defensins: (i) the carpet model and (ii) the pore model. In both models, defensins are described to interact with the negatively charged molecules present at the cell membrane of pathogens, causing an increase of its permeabilization, leading to cell leakage and death by necrosis. While the carpet model emphasizes the pore formation of several peptides into the membrane, the pore model shows that peptides form oligomers that, then, form multiple pores into the cell membrane. However, there is an alternative hypothesis, where defensins do not damage 


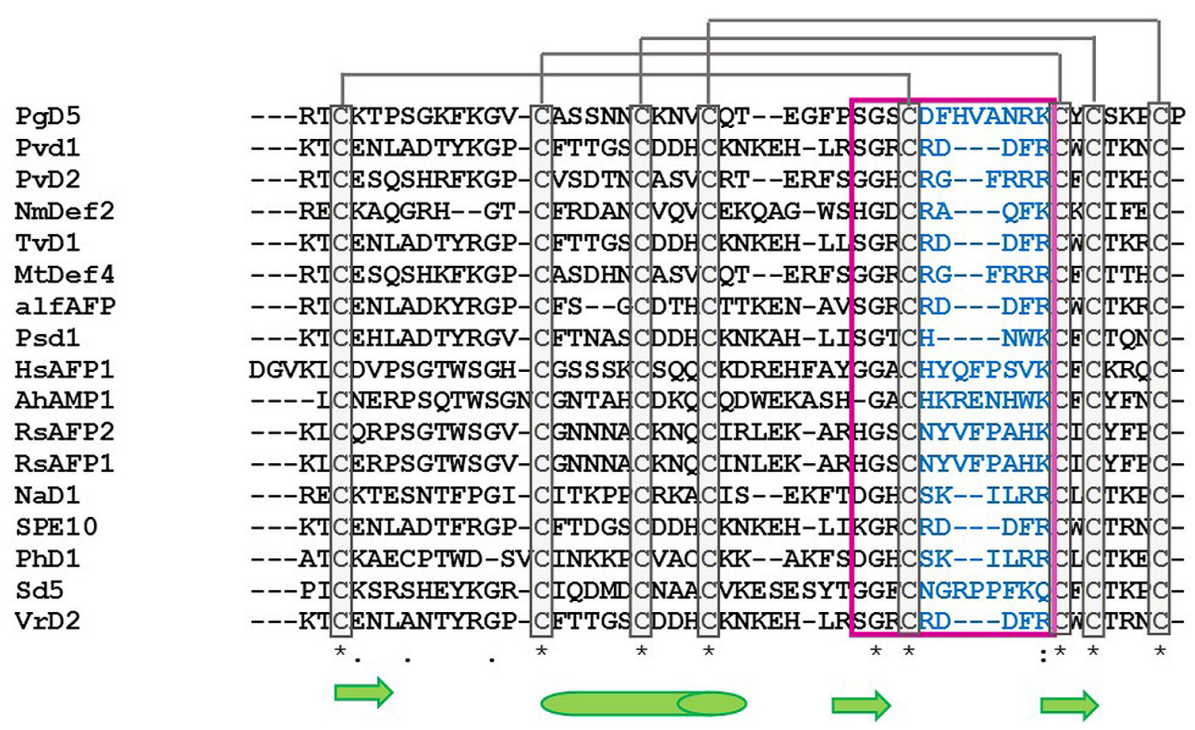

FIGURE 1 | Alignment of the amino acid sequence of antifungal plant defensins. PgD5: Picea glauca defensin (Accession: AAR84643); Pvd1: Phaseolus vulgaris defensin 1 (Accession: ADR30066); PvD2: Phaseolus vulgaris defensin 2 (Accession: ADR3006); NmDef1: Nicotiana megalosiphon defensin (Accession: ACR46857); TvD1: Tephrosia villosa defensin (Accession: AAX86993); MtDef4: Medicago trunculata defensin 4 (Accession: 2LR3_A); alfAFP: Medicago sativa antifungal peptide 1 (Accession: AAG40321); Psd1: Pisum sativum defensin 1 (Accession: 1JKZ_A); HsAFP1: Heuchera sanguinea antifungal peptide (Accession: P0C8Y5); AhAMP1: Aesculus hippocastanum antimicrobial peptide 1 (Accession: AAB34970); RsAFP1: Raphanus sativus antifungal peptide 1
(Accession: 1AYJ_A); RsAFP2: Raphanus sativus antifungal peptide 2 (Accession: P30230); NaD1: Nicotiana alata defensin 1 (Accession: 4ABO_A); SPE10: Pachyrrihizus erosus peptide (Accession: 3PSM_A); PhD1: Petunia hybrida defensin 1 (Accession: 1N4N_A); Sd5: Saccharum officinarum defensin 5 (Accession: 2KSK_A); VrD2: Vigna radiata defensin 2 (Accession: 2GL1_A). Asterisk indicates conserved cysteine amino acid residues among antifungal defensins (gray boxes). Gray lines represents the disulfide bridges between cysteine amino acid residues. Pink box and blue amino acid residues correspond to the $\gamma$-core region. Green arrows indicate $\beta$-sheet region and green cylinder indicate $\alpha$-helix region. Alignment was done using ClustalW2 Tool.
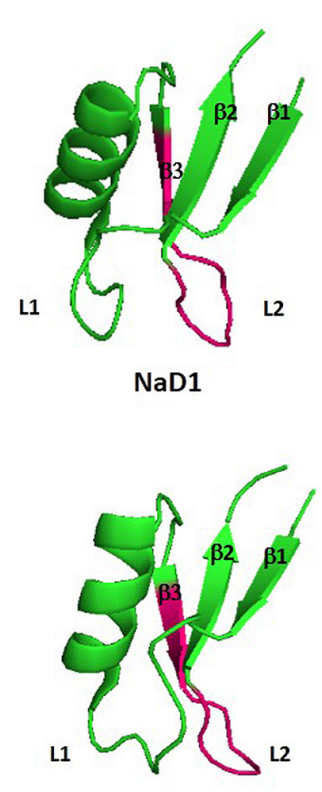

PhD1

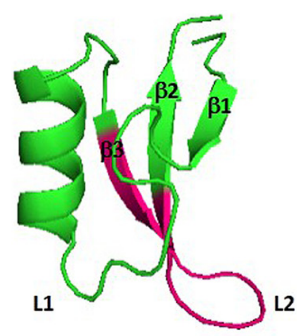

Rs-AFP1

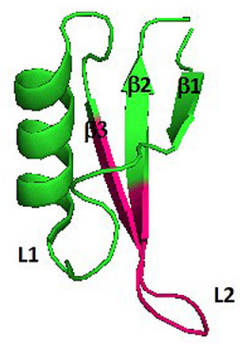

Sd5

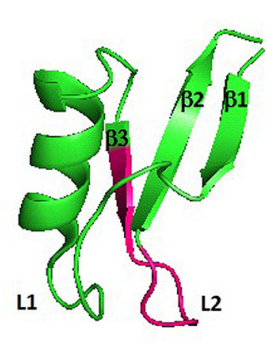

SPE10

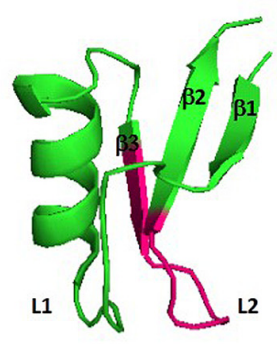

$\operatorname{VrD2}$
FIGURE 2 |Three-dimensional structure of six antifungal defensins from plants. Pink region highlight the $\gamma$-core motif of each peptide. $\beta 1$ : $\beta$-sheet 1 ; $\beta 2$ : $\beta$-sheet $2 ; \beta 3$ : $\beta$-sheet3; L1: Loop1; L2; Loop 2: NaD1: Nicotiana alata defensin 1 (Accession: 4ABO_A); Rs-AFP1: Raphanus sativus antifungal peptide 1 (Accession: 1AYJ_A); SPE10: Pachyrrihizus erosu peptide
(Accession: 3PSM_A); PhD1: Petunia hybrida defensin 1 (Accession: 1N4N_A); Sd5: Saccharum officinarum defensin 5 (Accession: 2KSK_A); VrD2: Vigna radiata defensin 2 (Accession: 2GL1_A). All figures were designed using PyMol Molecular Graphic System Version 1.2r3pre, Schrödinger, LLC. 
the cell membrane, but interact with the phospholipids, leading to an increase of ion permeability, or even to the transportation of these peptides to the intracellular environment (Wilmes et al., 2011; Hegedus and Marx, 2013). Hence, they can also enhance reactive oxygen species (ROS) and activate programmed cell death (PCD; Wilmes et al., 2011; Hegedus and Marx, 2013).

Moreover, positively charged amino acid residues were described to be important for antifungal activity, when located at loops and $\beta$-sheet regions. Hence, it was observed that the concave side of the VI $\beta$-turn from Rs-AFP1 was positively-charged, leading to the suggestion that the contact of this peptide with pathogenic fungi may occur through electrostatic interactions (De Samblanx et al., 1997; Fant et al., 1998). Other studies on the structural analyses of plant defensins, such as $\mathrm{NaD} 1$, described the importance of positively-charged amino acid residues at the loop region between $\beta 2$ and $\beta 3$, not only for antifungal activity, but for also functioning as a specificity factor towards different pathogens (Lay et al., 2003). Recently, it was reported that the amino acid residues located in the $\gamma$-core motif of MtDef4 are key tools for its antifungal activity and its specificity towards pathogenic fungi (Sagaram et al., 2011). First, in vitro assays using only the $\gamma$-core sequence of Mtdef4 and MsDef1 (alfAFP) showed that the high content of positively charged residues with the core of MtDef4 could, alone, provide antifungal activity, in contrary to the core of alfAFP, which was inactive against filamentous fungi (Sagaram et al., 2011). Later, mutagenesis studies on the region RGFRRR from MtDef4 showed that the substitution of the hydrophobic and positively-charged residues, Phe and Arg, at positions 3 and 4, respectively, by Ala residues decreased intensely its activity against fungi. Furthermore, it was shown that both defensins present differences on their kinetics of permeabilization, when assayed against Fusarium graminearum, as MtDef4 was able to induce a more potent antifungal activity and could take up the molecular probe SYTOX Green (SG) at a dependent concentration, indicating physical damage of cell membranes. In comparison, alfAFP induced a less effective membrane permeabilization, and did not induce a concentration dependent SG uptake (Sagaram et al., 2011).

Further reports displayed a comparison between the electrostatic potential surfaces of different defensins with their potential antimicrobial activities (Almeida et al., 2002). However, although there was no pattern of charge distribution among defensins, there was a high indication that plant defensins may act as potassium channel inhibitors, due to their similarities with neurotoxins, which contains residues for such activity (Almeida et al., 2002). Figure 3 shows the electrostatic surface area of three antifungal plant defensins (Phd1, Rs-AFP1, and VrD2), in which the site related to the second loop of the defensins that contains the $\gamma$-core region is described as the most important site for their antifungal activity. This is highly positively-charged in the cartoons where electrostatic surfaces were designed in vacuum. Therefore, it corroborates with the antifungal assays and the in silico studies performed by many researchers over the last 20 years.

A structural study on sugarcane defensin, Sd5, provided new information about the mechanism of action for those antifungal peptides. It was described that the hydrophobic core at the C-terminal of the defensin is also important for membrane interaction and permeabilization (de Paula et al., 2011). In

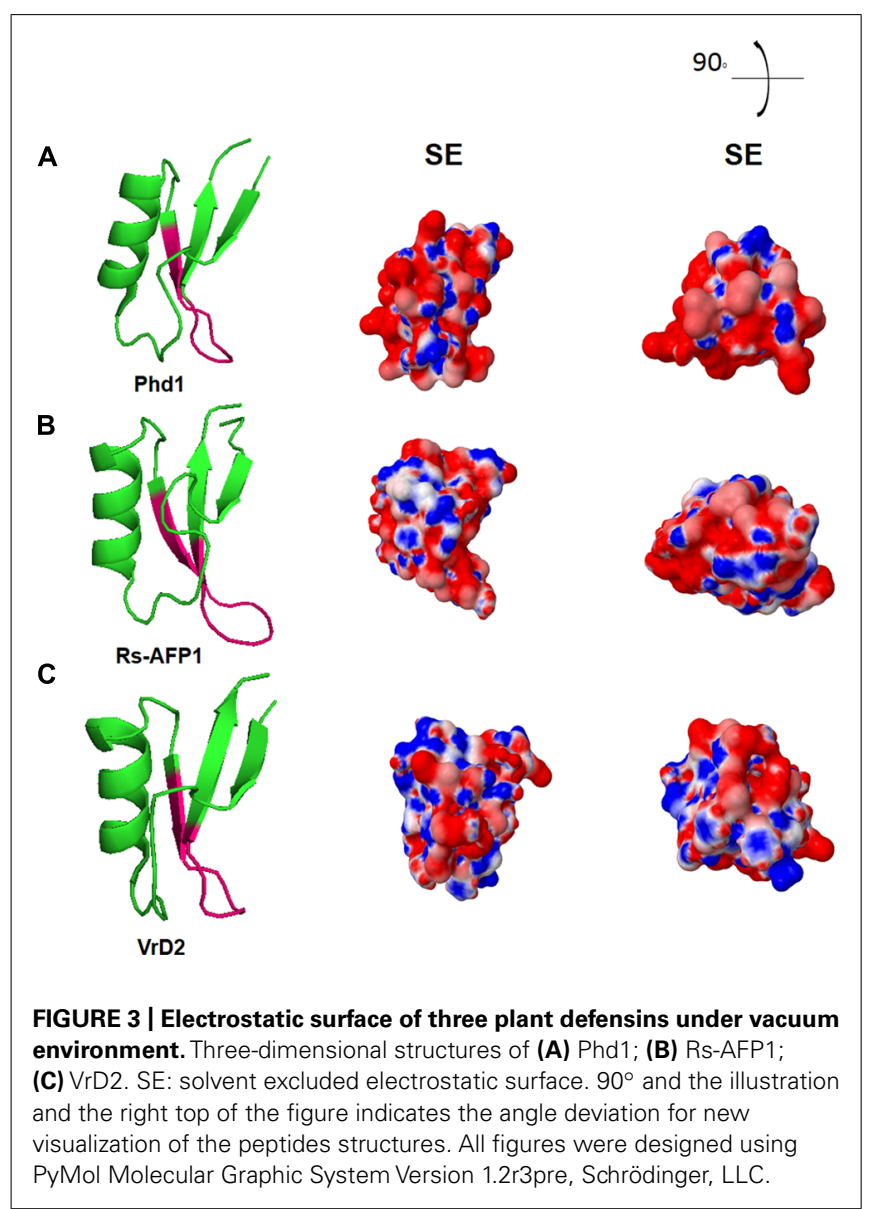

addition, evaluations on the backbone conformational dynamics of Sd5 suggest that the mechanisms of its structural exchange is related to modifications in the hydrogen bond distances of the $\beta$-sheet and $\alpha$-helix of the peptide, giving it the ability to bind to membranes. Hence, membrane permeabilization and vesicle leakage induced by Sd5 may occur through the interaction of the side chains of residues of three serines and the glycosyl part of the membrane model with glucosylceramide extracted from the hyphae of F. solani (de Paula et al., 2011). Recent studies on dynamics of Sd5 structure revealed that this peptide displays many dynamic properties. It was able to interact with a sphingolipid glycosylceramide $(\mathrm{CMH})$ membrane in a conformational selection process, which involved a specific binding, while other flexible regions of Sd5 showed to interact with the interface in a nonspecific manner (Valente et al., 2013).

Recent reports described the structural conformation of dimeric defensins being highly significant for its antifungal activity (Song et al., 2011; Figure 4). In this way, analyses of the defensin from Pachyrrihizus erosus, SPE10, provided the selection of the binding pattern Arg36-Trp42-Arg40 as essential for dimer formation. Moreover, it was demonstrated that Trp42 is fundamental for antifungal activity of plant defensins, as it is absent in nonantifungal peptides Therefore, dimers of SPE10 are arranged in a side-by-side manner with the $\alpha$-helix of one monomer interacting with the $\beta$-sheet of the second monomer, leading to a stretched 

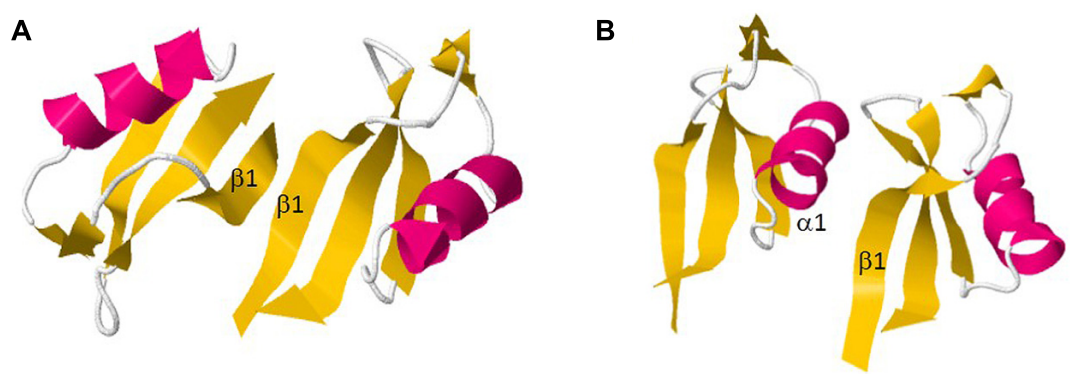

FIGURE 4 | Dimer formation of two plant defensins. (A) NaD1; (B) SPE10. All figures were designed using PyMol Molecular Graphic System Version 1.2r3pre, Schrödinger, LLC.

and twisted molecular surface. Conformational changes on Arg36 and Trp42 would alter the dimeric interface of SPE10, destabilizing the dimer (Song et al., 2011). In addition, the dimerization of the defensin $\mathrm{NaD} 1$ was performed in order to evaluate the relation between structural conformation and antifungal activity. In contrary to what was observed by SPE10 dimer, monomers of $\mathrm{NaD} 1$ were connected by a $\beta$-sheet $/ \beta$-sheet configuration, although the antifungal activity was maintained (Lay et al., 2012; Figure 4). Hence, plant defensins that form dimers coupled with their positively charged surface area become highly efficient molecules against pathogenic fungi, as they can strongly interact with the negatively charged glycoproteins located at the fungal cell walls (Lay et al., 2012).

\section{TARGETED FUNGI AND EFFECTIVE CONCENTRATIONS}

One of the first studies that attempted to highlight this class of plant antimicrobial defensins was carried out with two peptides isolated from Radish seeds, Rs-AFP1 and Rs-AFP2. Both peptides were assayed against 20 different plant pathogenic fungi and the lower protein concentration required for $50 \%$ inhibition of fungal growth $\left(\mathrm{IC}_{50}\right)$ was obtained by Rs-AFP2, when assayed against Pyricularia oryzae. Its $\mathrm{IC}_{50}$ ranged from 0.08 to $5 \mu \mathrm{M}$. Since that lots of defensins were reporter to show high biological activity in the range of micromolar to nanomolar as will soon be shown. Terras et al. (1992) were the first ones to report the importance of disulfide bonds to defensins stabilization and the role of inorganic ions in its antifungal activity. They also showed how thermostable defensins are, once they found that heating Rs-AFP1 and 2 at $100^{\circ} \mathrm{C}$ for $10 \mathrm{~min}$ did not affect antifungal properties of such molecules. The stability of such molecules is an important feature which allows wondering a wide range of biotechnological applications to plant defensins.

Few years after Terras report, Osborn et al. (1995) increased the knowledge about plant defensins and their effects under fungi. They assayed four AMP isolated from Aesculus hippocastanum (Ah-AMP1), Clitoria ternatea (Ct-AMP1), Dahlia merckii (DmAMP1), Heuchera sanguinea (Hs-AFP1) against eight different fungi in the presence, or absence, of inorganic ions. The lower $\mathrm{IC}_{50}$, around $0.1 \mu \mathrm{M}$, was acquired when Ah-AMP1 was tested towards Cladosporium sphaerospermum, Leptosphaeria maculans, and Septoria tritici. Hs-AFP1 presents the same antifungal activity when assayed against Septoria tritici. In all the studies, inorganic ions decreased $\mathrm{IC}_{50}$. When visualized under a microscope, it was possible to see that such antifungal peptides caused distinct morphological changes during germ tube elongation and hyphae development, like multiple hyphae buds or the diminished of the rate of germ tube elongation (Osborn et al., 1995; Table 1).

A great number of the earlier studies about the mechanism of action of plant defensins agree on the membrane permeabilization outcome (Thevissen et al., 1996, 1999). More recently, two peptides similar to plant defensins were reported to show such disruption power. The first one, from Phaseolus vulgaris, permeabilizes Mycosphaerella arachidicola membrane, among other fungi (Wong et al., 2012). The second, from Picea glauca, was reported to act on permeabilization of Verticillium dahlia membranes (Picart et al., 2012). Membrane permeabilization seems to be just one of a huge variety of mechanism of action for such molecules. While some results point to cellular membranes as the point of action, others suggest intracellular targets (Thevissen et al., 2000).

The use of antifungal peptide genes to generate important agronomical traits resistant to fungal disease have been seen with some skepticism by the biotechnological thinkers. Plant defensins proved to be useful for biotechnological purposes in the year of 2000, when Gao et al. (2000) showed that AlfAFP, an antifungal peptide from Medica sativa and active towards Verticillium dahliae, was expressed in a transgenic potato, increasing resistance against such filamentous fungus. The $\mathrm{IC}_{50}$ of AlfAFP towards Verticillium dahlia was determined at $1 \mu \mathrm{M}$, around ten times higher than the previous AMP described here (Gao et al., 2000). However, the resistance of transgenic potato expressing AlfAFP towards Verticillium dahliae showed to be more effective in greenhouse conditions and in the field than the chemical methods, what make of it a useful choice to plant transformation aiming resistance to phytopathogenic fungi, which will be discussed in detail later in this review.

Almeida et al. (2001) reported the heterologous expression of a Pisum sativum defensin (Psd1) in a eukaryotic expression, system based on the methilotrophic yeast Pichia pastoris. The high amount of Psd 1 produced by $P$. pastoris expression system $(13.8 \mathrm{mg} / \mathrm{L})$, allowed investigations about the conformational features between wide type and recombinant form of Psd1 (rPsd1). Besides being active towards filamentous fungi, such as Neurospora crassa, Psd1 did not demonstrate any activity against yeasts, even at high $(20 \mu \mathrm{M})$ concentrations (Almeida et al., 2000). According 
Table 1 | Short sample of plant defensins and its IC $_{50}$ concentration against its fungal targets.

\begin{tabular}{|c|c|c|c|c|}
\hline Plant defensin & Organism & Target organism & $I_{50}(\mu \mathrm{M})$ & Reference \\
\hline PgD5 & Picea glauca & Verticillium dahliae & 0,4 & Picart etal. (2012) \\
\hline Defensin-like peptide & Phaseolus vulgaris & Mycosphaerella arachidicola & 3,9 & Wong et al. (2012) \\
\hline NmDef02 & Nicotiana megalosiphon & Fusarium oxysporum & 1 & Portieles et al. (2010) \\
\hline Pdc1 & Zea mays & Fusarium graminearum & 0,75 & Kant et al. (2009) \\
\hline Limyin & Phaseolus limensis & Fusarium solani & 8,6 & Wang et al. (2009) \\
\hline TvD1 & Tephrosia villosa & Pheaoisariopsis personata & 1,9 & Vijayan et al. (2008) \\
\hline MtDef4 & Medicago truncatula & Fusarium graminearum & 0,75 & Ramamoorthy et al. (2007) \\
\hline MsDef1(alfAFP) & Medicago sativa & Fusarium graminearum & 1,2 & Spelbrink et al. (2004) \\
\hline Psd1 & Pisum sativum & Neurospora crassa & 2 & Almeida et al. (2001) \\
\hline alfAFP & Medicago sativa & Verticillium dahliae & 1 & Gao et al. (2000) \\
\hline HsAFP1 & Heuchera sanguinea & Septoria tritici & 0,1 & Osborn etal. (1995) \\
\hline AhAMP1 & Aesculus hippocastanum & Leptosphaeria maculans & 0,1 & Osborn etal. (1995) \\
\hline RsAFP2 & Raphanus sativus & Pyricularia oryzae & 0,08 & Terras etal. (1992) \\
\hline
\end{tabular}

to the report, the heterologous expression in Pichia pastoris did not significantly affect the defensin conformational features, and all post-translational modifications needed to its activity had been done. One of the small differences between Psd 1 and $\mathrm{rPsd} 1$ was their $\mathrm{N}$-terminal sequences. rPsd1 kept four amino acids residues from the recombinant signal peptide, and this seemed to be related to the 5-fold decrease on its activity towards F. solani and Aspergillus niger, in comparison to the wide type peptide. rPsd1 activity towards $N$. crassa was not affected, which suggests distinct modes of action of Psd1 against fungi belonging to different classes (Almeida et al., 2001). Furthermore, the Pichia pastoris system was also used to produce the recombinant Nicotiana megalosiphon defensin (NmDef02) active against F. oxysporum (Portieles et al., 2010).

Plant defensins have also been expressed in prokaryotic system and tested against fungi. TvD1, a defensin from Tephrosia villosa, was expressed in Escherichia coli and assayed towards Pheaoisariopsis personata (Vijayan et al., 2008; Table 1). A comparison between the expression of $\mathrm{Pdc1}$, a corn defensin, in yeast and E. coli was done and in both cases the peptide kept its antimicrobial activity, however, Pdcl expressed in yeast $\left(\mathrm{IC}_{50} 7.5 \mu \mathrm{M}\right.$ ) was more efficient than when expressed in E. coli $\left(\mathrm{IC}_{50} 30 \mu \mathrm{M}\right)$ in arrest F. graminearum growth. The presence or absence of a His-tag also influences its activity, suggesting that defensins are sensible to covalent modifications on its terminal ends (Kant et al., 2009).

Different from some results, which suggest the importance of N-terminus in defensin activity (Almeida et al., 2001), Spelbrink et al. (2004) demonstrated that the major determinant of antifungal activity of a defensin from Medicago sativa (MsDef1) resides in the carboxy-terminal region. They evaluated six different defensin chimeras obtained from molecular combinations of MsDef1, active towards F. graminearum. They also analyzed MtDef2, a defensin from Medicago truncatula, which did not have any activity towards F. graminearum. Among the six chimeras, only the ones harboring the MsDef1 portion on the C-terminal displayed some activity against F. graminearum (Spelbrink et al.,
2004). The divergence among results pointing to C-terminus and to $\mathrm{N}$-terminus as essentials to plant defensin activity, expose the uncertainty about the relation between structure and function of such molecules and even more on its modulation mechanism of activity.

Three years after Spelbrink findings, Ramamoorthy et al. (2007) tried to go a little deeper into the cellular mechanisms of activity modulation using Medicago defensins against F. graminearum. They have demonstrated that mutants of F. graminearum can react differently to Medicago defensins MsDef1 and MtDef4. F. graminearum mutant, whose MAP Kinase cascades were disrupted, were hypersensitive to MsDef1. However, it did not show any difference on its sensitivity to MtDef4. MAP kinase signaling cascades seemed to provide protection towards MsDef1, but not to MtDef4, which suggests that these plant defensins utilize specific signaling pathways to alter fungal growth (Ramamoorthy et al., 2007).

Besides antimicrobial activity, a plant defensin from Phaseolus limensis named Limyin and active against F. solani, were also reported to show antiproliferative activity towards human tumor cells (Wang et al., 2009), suggesting there are lots of things to be discovered about the cellular targets and mechanisms of action of plant defensins.

Plant defensins encompass a class of biomolecules with the potential to be explored as biotechnological tools towards phytopathogenic fungi, which nowadays, are controlled only by chemicals. The wide natural sources of these molecules and the heterogeneity of their action on different targets allow hundreds of possible biotechnological approaches that, together with their low effective concentration, as shown in Table 1, could lead to phytopathogeninc fungi control with less environmental impact.

\section{BIOTECHNOLOGICAL APPLICATIONS AND TRANSGENY}

Although there are many transformed plants in the market with additional genes coding to proteins that confer resistance towards herbicides and insect-pests, there is still no transgenic plant available against phytopathogenic fungi, nor even containing 
Table 2 | Antifungal defensins from plant sources used for transformation into foreign species.

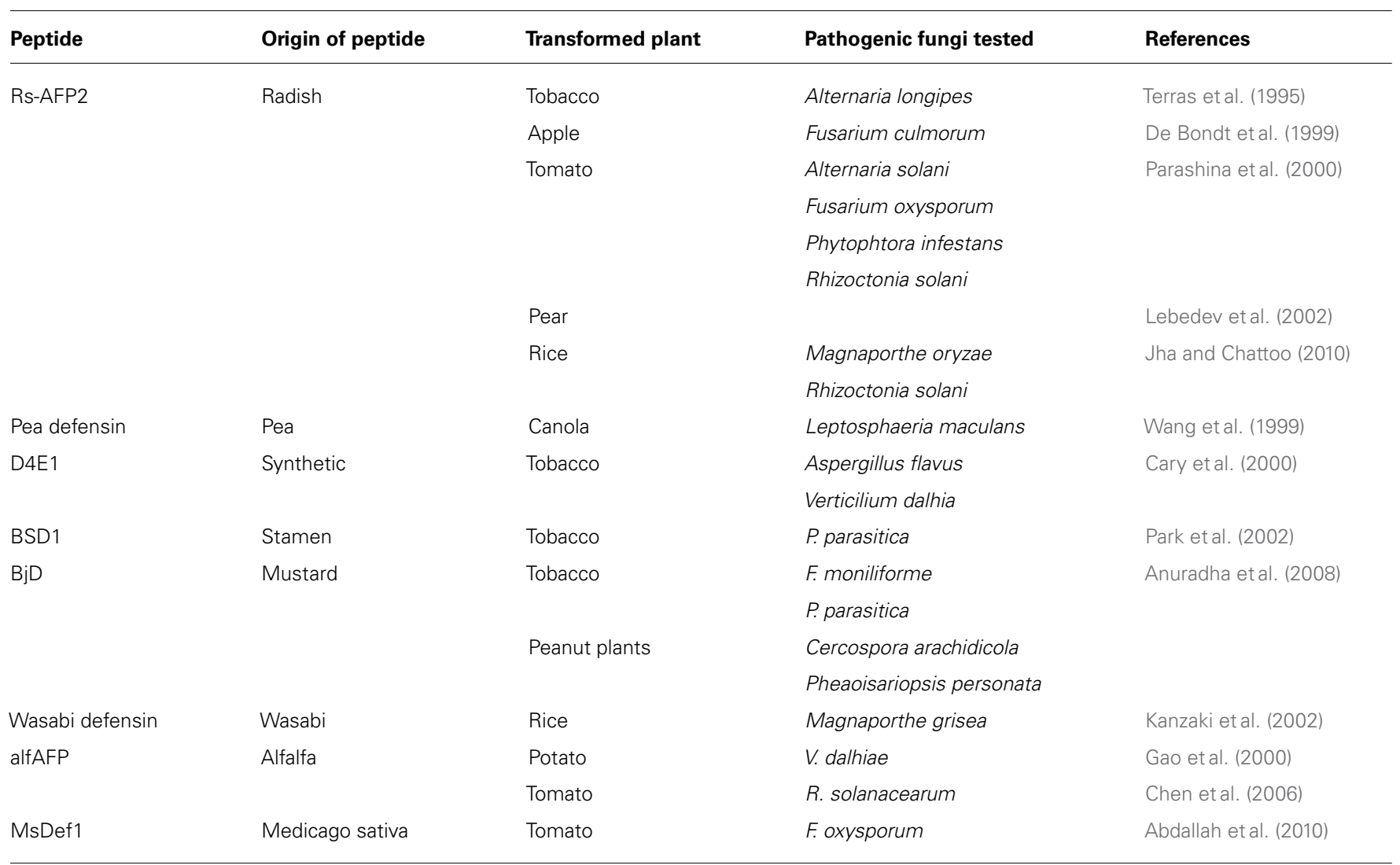

plant defensins as the resistant factor. Nevertheless, several studies describe the efficient activity of antifungal defensins when transformed into different host plants (Table 2). Therefore, plant defensins with antifungal activity have become the first molecule for the development of transgenic crops resistant to phytopathogens.

The first attempt to evaluate of transgenic plants containing foreigner antifungal defensin genes was done in tobacco plants expressing Rs-AFP2, a peptide from radish. High levels of peptide expression were observed in the transformed tobacco plants, as well as an increasing resistance towards the phytopathogenic fungus Alternatia longipes (Terras et al., 1995). Four years later, the same defensin was used for studies with transgenic apple plants and evaluation against pathogenic fungi species (De Bondt et al., 1999). Hence, after transformation through Agrobacterium tumefaciens, the transgenic plants were selected and the expressed peptide was isolated and quantified. In vitro assays showed that the recombinant peptide was able to inhibit the germination of Fusarium culmorum spores (De Bondt et al., 1999). Tomato lines have also been transformed with Rs-AFP2, generating the increase in their antifungal activity. In this study, leaves of tomato plants overexpressing the radish defensin were extracted and tested against some phytopathogenic fungi, including Alternatia solani, F. oxysporum, Phytophthora infestans, and Rhizoctonia solani (Parashina et al., 2000). It was demonstrated that the crude extract of tomato leaves containing the radish defensin could decrease the activity of all the fungi cited above.
Furthermore, in 2002, Rs-AFP2 was again evaluated in transgenic plants, this time using two pear cultivars - Burakovka and Pamyat' Yakoyleva. After transformation, leaves of pear plants were collected for PCR and Western Blot Hybridization analyses. The presence of the foreigner gene and recombinant peptide were detected through the respective techniques, confirming the success of plant transformation (Lebedev et al., 2002). Nevertheless, in vitro and in vivo assays against pathogen fungi are still to be done in order to check the antifungal activity of transgenic pear plants expressing Rs-AFP2. The most recent work on Rs-AFP2 was published in 2010, when Jha and Chattoo (2010) transformed this peptide into rice (Oryza sativa L. cv. Pusa basmati 1). The transgenic plants were tested in vitro and in vitro against Magnaporthe oryzae and Rhizoctonia solani, the main causes of rice losses in agriculture, revealing that overexpression of Rs-AFP2 can control the rice blast and sheath blight diseases (Jha and Chattoo, 2010).

In addition, other works on transgenic plants expressing an antifungal defensin were published. Hence, it was demonstrated that pea defensins transformed into Brassica napus cultivars enhanced their resistance against Leptosphaeria maculans, which causes blackleg diseases in plants (Wang et al., 1999). Tobacco plants transformed via Agrobacterium tumefasciens and containing a synthetic antifungal gene was also performed. The expressed peptide, named D4E1, provided an increasing resistance of tobacco against Aspergillus flavus and Verticillium dahlia (Cary et al., 2000). Tobacco was also used for transformation of the stamen 
defensin BSD1, where the expressed peptide provided higher tolerance to the plant against the attack of Phytophtora parasitica (Park etal., 2002). Transformation of tobacco with the mustard defensin - BjD - once more validated the potential of these peptide-family members as excellent antifungal agents, as transgenic plants displayed improved resistance towards $F$. moniliforme and Phytophtora parasitica (Anuradha et al., 2008). More recently, a defensin purified from maize, ZmDEF1, when transformed into tobacco plants, showed increased tolerance against Phytophtora parasitica (Wang et al., 2011). Transgenic peanut plants, expressing the same mustard defensin, also provided an enhancement of tolerance against Cercospora arachidicola and Pheaoisariopsis personata, which mutually cause the late leaf spot disease (Anuradha et al., 2008).

Kanzaki et al. (2002) performed a successful attempt of expressing a defensin from Wasabia japonica into rice plants, as an effort to increase the plant resistance against the phytopathogenic fungus Magnaporthe grisea. Moreover, they showed that T3-generation transformed rice plants could still overexpress the wasabi defensin and maintain its ability to control Magnaporthe grisea in vivo. Earlier, it was demonstrated that transgenic potato expressing an antifungal defensin from alfalfa (alfAFP) was more resistant to the attack of Verticillium dahliae, when compared to nontransformed plants (Gao et al., 2000). A summary of information of expressed plant defensins into plant cultivars can be seen at Table 2.

An attempt at transforming two different genes at the same time in tomato plants was performed using genetic material of a defensin and a glucanase from alfalfa, in order to analyze their efficiency towards phytopathogenic fungi. Therefore, T1-generation transgenic plants revealed enhanced tolerance to $R$. solanacearum, when compared to non-transformed plants, indicating the existence of a synergic effect of both proteins as antifungal molecules in tomato cultivars (Chen et al., 2006). Further efforts using other plant defensins into transformed tomato plants were carried out. In this way, Abdallah et al. (2010) inserted the Medicago sativa defensin gene into Licopersicum esculentum cultivar CastleRock and evaluated the transformed plants against the pathogenic fungus F. oxysporum f. sp. Lycopersici. In vivo assays demonstrated that T1- and T2-generations of transgenic tomato plants presented increased resistance against the fungal pathogen, when compared to non-transformed plants.

Plant defensins have also displayed indirect responses towards phytopathogenic fungi in transgenic plants, when other foreigner genes are being overexpressed (Murad et al., 2007). Hence, earlier reports showed that a peptide from Arabidopsis thaliana, named AtPep1 stimulated the transcription activation of the defensin gene pdf1.2 (Huffaker et al., 2006). When AtPep1 precursor gene PROPEP1 was expressed into transgenic Arabidopsis plants, the transcription of PDF1.2 was also observed. Moreover, the expressed defensin stimulated root development, which, consequently, improved plant resistance against the filamentous fungus Pythium irregular (Huffaker et al., 2006).

Similar results were obtained when an ionotropic glutamate receptor (RsGluR) was transformed into Arabidopsis plants. The expression of RsGluR led to an up-regulation of defensins, causing an increase of the plant resistance towards Botrytis cinerea (Kang et al., 2006). Microarray analyses later confirmed that up-regulated defensins and jasmonic acid-responsive genes were produced after overexpression of RsGluR in Arabidopsis. Furthermore, the same plant species was transformed with a cotton nonsymbiotic hemoglobin for tolerance against fungal pathogens. However, the foreigner gene could also induce a constitutive expression of the PR protein K (PR-1) as well as the defensin PDF1.2, providing an enhanced resistance to Verticillium dahliae (Qu et al., 2006).

\section{CONCLUSION AND PERSPECTIVES}

Plant defensins correspond to a world of possibilities for defense mechanisms, and new peptides with different activities are still to be discovered, as well, studies with thousands of plant species need to be performed. Nowadays, several peptides already show satisfactory efficacy against such pathogens with strong potential to be applied for the production of a commercial fungicide or application into transgenic plants. But, the question remains. Why is there still no product containing antifungal plant defensins in its natural form or in nanocapsules - already available in the market?

It is interesting that plant defensins with antifungal peptides are mostly studied for pathogens located in tropical areas, including Latin American, African, and some Asian countries. Moreover, the loss of commercially important crops due to the attack of phytopathogenic fungi is considered worldwide, until now, less detrimental than the losses caused by drought stress and insectpests. Therefore, the efforts focused on the release of novel plant varieties resistant to drought stress and insect-pests are more significant, as there is mounting pressure to control these adversities in order to provide an increase in crop production. However, the development of transgenic plants expressing antifungal defensins or the production of defensin-based biofungicide depends, mainly, on the determination of regional research teams focusing on specific fungal targets, so these products can reach the market.

Furthermore, there is a long process required for analyzing the efficiency, environmental risks, safety towards animal and human consumption, and reproducibility of transformed plants expressing certain molecules, as well as the need for having an extremely stable, effective, and easy-to-produce peptide to be used in the fabrication of a biofungicide. Therefore, it is possible that there are already plant defensin-based products on the horizon that will soon be released on to the market.

Also, it is expected that, in the near future, antifungal defensinbased commercial agro-products be targeted as essential for the increase of crop production. This will stimulate and accelerate the transition between biotechnological research and field application of bioproducts.

\section{ACKNOWLEDGMENTS}

The authors are thankful for the financial support of CAPES, CNPq, and Embrapa.

\section{REFERENCES}

Abdallah, N. A., Shah, D., Abbas, D., and Madkour, M. (2010). Stable integration and expression of a plant defensin in tomato confers resistance to Fusarium wilt. GM Crops 1, 344-350. doi: 10.4161/gmcr.1.5.15091 
Almeida, M. S., Cabral, K. M. S., Zingali, R. B., and Kurtenbach, E. (2000). Characterization of two novel defense peptides from pea (Pisum sativum) seeds. Arch. Biochem. Biophys. 378, 276-278. doi: 10.1006/abbi.2000.1824

Almeida, M. S., Cabral, K. S., de Medeiros, L. N., Valente, A. P., Almeida, F. C. L., and Kurtenbach, E. (2001). cDNA cloning and heterologous expression of functional cysteine-rich antifungal protein Psd1 in the yeast Pichia pastoris. Arch. Biochem. Biophys. 395, 199-207. doi: 10.1006/abbi.2001.2564

Almeida, M. S., Cabral, K. M. S., Kurtenbach, E., Almeida, F. C. L., and Valente, A. P. (2002). Solution structure of Pisum sativum defensin 1 by high resolution NMR: plant defensins, identical backbone with different mechanisms of action. J. Mol. Biol. 315, 749-757. doi: 10.1006/jmbi.2001.5252

Anuradha, T. S., Divya, E. K., Jami, E. S. K., and Kirti, E. P. B. (2008). Transgenic tobacco and peanut plants expressing a mustard defensin show resistance to fungal pathogens. Plant Cell Rep. 27, 1777-1786. doi: 10.1007/s00299-0080596-8

de Beer, A., and Vivier, M. A. (2011). Four plant defensins from an indigenous South African Brassicaceae species display divergent activities against two test pathogens despite high sequence similarity in the encoding genes. BMC Res. Notes 4:459. doi: 10.1186/1756-0500-4-459

Benko-Iseppon, A. M., Galdino, S. L., Calsa, T. J., Kido, E. A., Tossi, A., Belarmino, L. C., et al. (2010). Overview on plant antimicrobial peptides. Curr. Prot. Pept. Sci. 11, 181-188. doi: 10.2174/138920310791112075

Broekaert, W. F., Cammue, B., DeBolle, M., Thevissen, K., DeSamblanx, G., and Osborn, R. (1997). Antimicrobial peptides from plants. Crit. Rev. Plant Sci. 16 297-323. doi: 10.1080/07352689709701952

Broekaert, W. F., Terras, F. R. G., Cammue, B. P. A., and Osborn, R. W. (1995) Plant Defensins - novel antimicrobial peptides as components of the host-defense system. Plant Physiol. 108, 1353-1358. doi: 10.1104/pp.108.4.1353

Bruix, M., Gonzalez, C., Santoro, J., Soriano, F., Rocher, A., Ménez, E., et al. (1995). $1 \mathrm{H}-\mathrm{NMR}$ studies on the structure of a new thionin from barley endosperm. Biopolymers 36, 751-763. doi: 10.1002/bip.360360608

Carvalho, A. O., and Gomes, V. M. (2009). Plant defensins - prospects for the biological functions and biotechnological properties. Peptides 30, 1007-1020. doi: 10.1016/j.peptides.2009.01.018

Carvalho, A. O., and Gomes, V. M. (2011). Plant defensins and defensin-like peptides - biological activities and biotechnological applications. Curr. Pharm. Design. 17, 4270-4293. doi: 10.2174/138161211798999447

Cary, J. W., Rajasekaran, K., Jaynes, J. M., and Cleveland, T. E. (2000). Transgenic expression of a gene encoding a synthetic antimicrobial peptide results in inhibition of fungal growth in vitro and in planta. Plant Sci. 154, 171-181. doi: 10.1016/S0168-9452(00)00189-8

Chen, K.-C., Lin, C.-Y., Chung, M.-C., Kuan, C. C., Sung, H. Y., Tsou, S. C. S., et al. (2002). Cloning and characterization of a cDNA encoding an antimicrobial protein from mung bean seeds. Bot. Bull. Acad. Sin. 43, 251-259.

Chen, S. C., Liu, A. R., and Zou, Z. R. (2006). Overexpression of glucanase gene and defensin gene in transgenic tomato enhances resistance to Ralstonia solanacearum. Russia J. Plant Physiol. 53, 756-763. doi: 10.1134/S1021443706050116

Colilla, F. J., Rocher, A., and Mendez, E. (1990). Gamma-purothionins: animo acid sequence of two polypeptides of a new family of thionins from wheat endosperm. FEBS Lett. 270, 191-194. doi: 10.1016/0014-5793(90)81265-P

De Bondt, A., Zaman, S., Broekaert, W., Cammue, B., and Keulemans, J. (1999). Genetic transformation of apple (Malus pumila Mill.) for increased fungal resistance: in vitro antifungal activity in protein extracts of transgenic apple expressing Rs-AFP2 or Ace-AMP1. Acta Hort. 484, 565-570.

De Coninck, B., Cammue B. P. A., and Thevissen, K. (2013). Modes of antifungal action andin planta functions of plant defensins and defensin-like peptides. Fungal Biol. Rev. 26, 109-120. doi: 10.1016/j.fbr.2012.10.002

de Paula, V. S., Razzera, G., Barreto-Bergter, E., Almeida, F. C. L., and Valente, A. P. (2011). Portrayal of complex dynamic properties of sugarcane defensin 5 by NMR: multiple motions associated with membrane interaction. Structure 19, 26-36. doi: 10.1016/j.str.2010.11.011

De Samblanx, G. W., Goderis, I. J., Thevissen, K., Raemaekers, R., Fant, F., Borremans, F. A. M., et al. (1997). Mutational analysis of a plant defensin from radish (Raphanus sativus L.) reveals two adjacent sites important for antifungal activity. J. Biol. Chem. 272, 1171-1179. doi: 10.1074/jbc.272.2.1171

Fant, F., Vranken, W., Broekaert, W., and Borremans, F. (1998). Determination of the three-dimensional solution structure of Raphanus sativus antifungal protein 1 by 1HNMR. J. Mol. Biol. 279, 257-270. doi: 10.1006/jmbi.1998.1767
Franco, O. L. (2011). Peptide promiscuity: an evolutionary concept for plant defense. FEBS Lett. 585, 995-1000. doi: 10.1016/j.febslet.2011.03.008

Gachomo, E. W., Seufferheld, M. J., and Kotchoni, S. O. (2010). Melanization of appressoria is critical for the pathogenicity of Diplocarpon rosae. Mol. Biol. Rep. 37, 3583-3591. doi: 10.1007/s11033-010-0007-4

Gachomo, E. W., Shonukan, O. O., and Kotchoni, S. O. (2003). The molecular initiation and subsequence acquisition of disease resistance in plants. Afr. J. Biotechnol. 2, 26-32.

Gao, A.-G., Hakimi, S. M., Mittanck, C. A., Wu, Y., Woerner, B. M., Stark, D. M., et al. (2000). Fungal pathogen protection in potato by expression of a plant defensin peptide. Nat. Biotechnol. 18, 1307-1310. doi: 10.1038/82436

Garcia-Olmedo, F., Molina, A., Alamillo, J. M., and Rodriguez-Palenzuela, P. (1998). Plant defense peptides. Biopolymers 47, 479-491. doi: 10.1002/(SICI)10970282(1998)47:6<479::AID-BIP6>3.0.CO;2-K

Hegedus, N., and Marx, F. (2013). Antifungal proteins: more than antimicrobials? Fungal Biol. Rev. 26, 132-145. doi: 10.1016/j.fbr.2012.07.002

Huffaker, A., Pearce, G., and Ryan, C. A. (2006). An endogenous peptide signal in Arabidopsis activates components of the innate immune response. Proc. Natl. Acad. Sci. U.S.A. 103, 10098-10103. doi: 10.1073/pnas.0603727103

Janssen, B. J. C., Schirra, H. J., Lay, F. T., Anderson, M. A., and Craik, D. J. (2003). Structure of Petunia hybrid defensin 1, a novel plant defensin with five disulfide bonds. Biochemistry 42, 8214-8222. doi: 10.1021/bi034379o

Jha, S., and Chattoo, B. B. (2010). Expression of a plant defensin in rice confers resistance to fungal phytopathogens. Transg. Res. 19, 373-384. doi: 10.1007/s11248-009-9315-7

Kang, S., Kim, H. L., Le, H., Choi, J.-Y., Heu, H., Oh, C.-J., et al. (2006). Overexpression of Arabidopsis of a plasma membrane-targeting glutamate receptor from small radish increases glutamate-mediated $\mathrm{Ca}+2$ influx and delays fungal infection. Mol. Cells 21, 418-427.

Kant, P., Liu, W. Z., and Pauls, P. K. (2009). PDC1, a corn defensin peptide expressed in Escherichia coli and Pichia pastoris inhibits growth of Fusarium graminearum. Peptides 30, 1593-1599. doi: 10.1016/j.peptides.2009.05.024

Kanzaki, H., Nirasawa, S., Saitoh, H., Ito, M., Nishihara, M., Terauchi, R., et al. (2002). Overexpression of the wasabi defensin gene confers enhanced resistance to blast fungus (Magnaporthe grisea) in transgenic rice. Theor. Appl. Genet. 105, 809-814. doi: 10.1007/s00122-001-0817-9

Kobayashi, Y., Sato, A., Takashima, H., Tamaoki, H., Nishimura, S., Kyogoku, Y., et al. (1991). A new $\alpha$-helical motif in membrane active peptides. Neurochem. Internat. 18, 525-534. doi: 10.1016/0197-0186(91)90151-3

Kragh, K. M., Nielsen, J. E., Nielsen, K. K., Dreboldt, S., and Mikkelsen, J. D. (1995). Characterization and localization of new antifungal cysteine-rich proteins from Beta vulgaris. Mol. Plant Microbe Interact. 8, 424-434. doi: 10.1094/MPMI-8-0424

Lay, F. T., and Anderson, M. A. (2005). Defensins - components of the innate immune system in plants. Curr. Protein Pept. Sci. 6, 85-101. doi: $10.2174 / 1389203053027575$

Lay, F. T., Mills, G. D., Poon, I. K. H., Cowieson, N. P., Kirby, N., Baxter, A. A., et al. (2012). Dimerization of plant defensin NaD1 enhances its antifungal activity. J. Biol. Chem. 287, 19961-19972. doi: 10.1074/jbc.M111.331009

Lay, F. T., Schirra, H. J., Scalon, M. J., Anderson, M. A., and Craik, D. J. (2003). The three-dimensional solution structure of $\mathrm{NaD} 1$, a new floral defensin from Nicotiana alata and its application to a homology model of the crop defense protein alfAFP. J. Mol. Biol. 325, 175-188. doi: 10.1016/S0022-2836(02) 01103-8

Lebedev, V. G., Dolgov, S. V., Lavrova, N., Lunin, V. G., and Naroditski, B. S. (2002). Plant-Defensin Genes Introduction for Improvement of Pear Phytopathogen Resistance. ISHS Acta Horticulturae 596. VIII International Symposium on Pear, Ferrara-Bologna, Italy.

Mendez, E., Moreno, A., Colilla, F., Pelaez, F., Lima, G. G., Mendez, R., et al. (1990). Primary structure and inhibition of protein synthesis in eukaryotic cellfree system of a novel thionin, - hordothionin, from barley endosperm. Eur. J. Biochem. 194, 533-539. doi: 10.1111/j.1432-1033.1990.tb15649.x

Murad, A. M., Pelegrini, P. B., Neto, S. M., and Franco, O. L. (2007). Novel findings of defensins and their utilization in construction of transgenic plants. Trans. Plant J. 1, 39-48.

Osborn, R. W., Desamblanx, G. W., Thevissen, K., Goderis, I., Torrenkens, S., Vanleuven, F., et al. (1995). Isolation and characterization of plant defensins from seeds of asteraceae, fabaceae, hippocastanaceae and saxifragaceae. FEBS Lett. 368, 257-262. doi: 10.1016/0014-5793(95)00666-W 
Osbourn, A. E. (1999). Antimicrobial phytoprotectants and fungal pathogens: a commentary. Fungal Genet. Biol. 26, 163-168. doi: 10.1006/fgbi.1999.1133

Parashina, E. V., Serdobinskii, L. A., Kalle, E. G., Lavrova, N. V., Avetisov, V. A., Lunin, V. G., et al. (2000). Genetic engineering of oilseed rape and tomato plants expressing a radish defensin gene. Russian J. Plant Physiol. 47, 417-423.

Park, H. C., Kang, Y. H., Chun, H. J., Koo, J. C., Cheong, Y. H., Kim, C. Y., et al. (2002). Characterization of a stamen-specific cDNA encoding a novel plant defensin in Chinese cabbage. Plant Mol. Biol. 50, 57-68. doi: 10.1023/A:10160052 31852

Pelegrini, P. B., and Franco, O. L. (2005). Plant $\gamma$-thionins: novel insights on the mechanism of action of a multi-functional class of defense proteins. Int. J. Biochem. Cell Biol. 37, 2239-2253. doi: 10.1016/j.biocel.2005.06.011

Picart, P., Pirttila, A. M., Raventos, D., Kristensen, H. H., and Sahl, H. G. (2012). Identification of defensin-encoding genes of Picea glauca: characterization of $\mathrm{PgD} 5$, a conserved spruce defensin with strong antifungal activity. BMC Plant Biol. 12:180. doi: 10.1186/1471-2229-12-180

Portieles, R., Ayra, C., Gonzalez, E., Gallo, A., Rodriguez, R., Chacon, O. et al. (2010). NmDef02, a novel antimicrobial gene isolated from Nicotiana megalosiphon confers high-level pathogen resistance under greenhouse and field conditions. Plant Biotech. J. 8, 678-690. doi: 10.1111/j.1467-7652.2010. 00501.x

Qu, Z.-L., Zhong, N.-Q., Wang, H.-Y., Chen, A.-P., Jian, G.-L., and Xia, G.-X. (2006). Ectopic expression of the cotton non-symbiotic hemoglobin gene GhHb triggers defense responses and increases disease tolerance in Arabidopsis. Plant Cell Physiol. 47, 1058-1068. doi: 10.1093/pcp/pcj076

Ramamoorthy, V., Zhao, X. H., Snyder, A. X., Xu, J. R., and Shah, D. M. (2007). Two mitogen-activated protein kinase signaling cascades mediate basal resistance to antifungal plant defensins in Fusarium graminearum. Cell. Microbiol. 9, 14911506. doi: 10.1111/j.1462-5822.2006.00887.x

Sagaram, U. S., Pandurangi, R., Karu, J., Smith, T. J., and Shah, D. M. (2011). Structure-activity determinants in antifungal plant defensins MsDefl and MtDef4 with different modes of action against Fusarium graminearum. PLoS ONE 6:e18550. doi: 10.1371/journal.pone.0018550

Segura, A., Moreno, M., Molina, A., and García-Olmedo, F. (1998). Novel defensin subfamily from spinach (Spinacia oleracea). FEBS Lett. 435, 159-162. doi 10.1016/S0014-5793(98)01060-6

Selitrennikoff, C. P. (2001). Antifungal proteins. App. Environ. Microbiol. 67, 2883 2894. doi: 10.1128/AEM.67.7.2883-2894.2001

Song, X., Zhang, M., Zhou, Z., and Gong, W. (2011). Ultra-high resolution crystal structure of a dimeric defensin SPE10. FEBS Lett. 585, 300-306. doi 10.1016/j.febslet.2010.12.039

Spelbrink, R. G., Dilmac, N., Allen, A., Smith, T. J., Shah, D. M., and Hockerman, G. H. (2004). Differential antifungal and calcium channel-blocking activity among structurally related plant defensins. Plant Physiol. 135, 2055-2067. doi 10.1104/pp.104.040873

Terras, F. R. G., Eggermont, K., Kovaleva, V., Raikel, N. V., Osborn, R. W., Kester A., et al. (1995). Small cysteine-rich antifungal proteins from radish: their role in host defense. Plant Cell. 7, 573-88. doi: 10.1105/tpc.7.5.573

Terras, F. R. G., Schoofs, H. M. E., Debolle, M. F. C., Vanleuven, F., Rees, S. B. Vanderleyden, J., et al. (1992). Analysis of 2 novel classes of plant antifungal proteins from radish (Raphanus-sativus 1) seeds. J. Biol. Chem. 267, 15301-15309.

Thevissen, K., Cammue, B. P. A., Lemaire, K., Winderickx, J., Dickson, R. C., Lester R. L., et al. (2000). A gene encoding a sphingolipid biosynthesis enzyme determines the sensitivity of Saccharomyces cerevisiae to an antifungal plant defensin from dahlia (Dahlia merckii). Proc. Natl. Acad. Sci. U.S.A. 97, 9531-9536. doi: 10.1073/pnas.160077797

Thevissen, K., Ghazi, A., DeSamblanx, G. W., Brownlee, C., Osborn, R. W., and Broekaert, W. F. (1996). Fungal membrane responses induced by plant defensins and thionins. J. Biol. Chem. 271, 15018-15025. doi: 10.1074/jbc.271.25.15018
Thevissen, K., Terras, F. R. G., and Broekaert, W. F. (1999). Permeabilization of fungal membranes by plant defensins inhibits fungal growth. App. Environ. Microbiol. 65, 5451-5458.

Valente, A. P., de Paula, V. S., and Almeida, F. C. L. (2013). Revealing the Properties of plant defensins through dynamics. Molecules 18, 11311-11326. doi: 10.3390/molecules180911311

Van der Weerden, N., and Anderson, M. A. (2013). Plant defensins: commons fold, multiple functions. Fungal Bio. Rev. 26, 121-131. doi: 10.1016/j.fbr.2012.08.004

Van Loon, L. C., Rep, M., and Pieterse, C. M. J. (2006). Significance of inducible defense-related proteins in infected plants. Ann. Rev. Phytopathol. 44, 135-162. doi: 10.1146/annurev.phyto.44.070505.143425

Vijayan, S., Guruprasad, L., and Kirti, P. B. (2008). Prokaryotic expression of a constitutively expressed Tephrosia villosa defensin and its potent antifungal activity. App. Microbiol. Biotechnol. 80, 1023-1032. doi: 10.1007/s00253-008-1648-2

Wang, Y. P., Nowak, G., Culley, D., Hadwiger, L. A., and Fristensky, B. (1999). Constitutive expression of pea defensin gene DRR206 confers resistance to blackleg (Leptosphaeria maculans) disease in transgenic canola (Brassica napus). Mol. Plant. Microbe Interact. 12, 410-418. doi: 10.1094/MPMI.1999.12. 5.410

Wang, S., Rao, P., and Ye, X. (2009). Isolation and biochemical characterization of a novel leguminous defense peptide with antifungal and antiproliferative potency. Appl. Microbiol. Biotechnol. 82, 79-86. doi: 10.1007/s00253-0081729-2

Wang, B., Yu, J., Zhu, D., and Zhao, Q. (2011). Maize defensin ZmDEF1 is involved in plant response to fungal phytopathogens. African J. Biotech. 10, 16128-16137.

Wilmes, M., Cammuer, B. P. A., Sahl, H.-G., and Thevisse, K. (2011). Antibiotic activities of host defense peptides: more to it than lipid bilayer perturbation. Nat. Prod. Rep. 28, 1350-1358. doi: 10.1039/clnp00022e

Wong, J. H., Ip, D. C. W., Ng, T. B., Chan, Y. S., Fang, F., and Pan, W. L. (2012). A defensin-like peptide from Phaseolus vulgaris cv. "King Pole Bean." Food Chem. 135, 408-414. doi: 10.1016/j.foodchem.2012.04.119

Yount, N. Y., Andrés, M. T., Fierro, J. F., and Yeaman, M. R. (2007). The gammacore motif correlates with antimicrobial activity in cysteine-containing kaliocin-1 originating from transferrins. Biochim. Biophys. Acta. 1768, 2862-2872. doi: 10.1016/j.bbamem.2007.07.024

Yount, N. Y., and Yeaman, M. R. (2004). Multidimensional signatures in antimicrobial peptides. Proc. Natl. Acad. Sci. U.S.A. 101, 7363-7368. doi: 10.1073/pnas.0401567101

Zhu, S., Gao, B., and Tytgat, J. (2005). Phylogenetic distribution, functional epitopes and evolution of the CSab superfamily. Cell Mol. Life Sci. 62, 2257-2269. doi: $10.1007 / \mathrm{s} 00018-005-5200-6$

Conflict of Interest Statement: The authors declare that the research was conducted in the absence of any commercial or financial relationships that could be construed as a potential conflict of interest.

Received: 10 August 2013; accepted: 07 March 2014; published online: 02 April 2014. Citation: Lacerda AF, Vasconcelos ÉAR, Pelegrini PB and Grossi de Sa MF (2014) Antifungal defensins and their role in plant defense. Front. Microbiol. 5:116. doi: 10.3389/fmicb.2014.00116

This article was submitted to Antimicrobials, Resistance and Chemotherapy, a section of the journal Frontiers in Microbiology.

Copyright (c) 2014 Lacerda, Vasconcelos, Pelegrini and Grossi de Sa. This is an open-access article distributed under the terms of the Creative Commons Attribution License (CC BY). The use, distribution or reproduction in other forums is permitted, provided the original author(s) or licensor are credited and that the original publication in this journal is cited, in accordance with accepted academic practice. No use, distribution or reproduction is permitted which does not comply with these terms. 